\title{
A MEMÓRIA VIVA gerada por Jerusa
}

Feliciano José Bezerrả Filho (UESDI)

Falar de Jerusa Pires Ferreira é expressar um lugar de pensamento e ação, é aceitar o envolvimento do diálogo intermitente entre culturas, entre planos de reflexão intelectual e imersão corporal.

O cruzamento de ideias é próprio de seu modo de articular o pensamento, que investe em muitas possibilidades de avaliação crítica das redes teóricas disponibilizadas, dos sistemas que prefiguram, analiticamente, o homem, a cultura e seus encaixes e desencaixes. Assim, devemos aceitá-la como uma operadora da cultura enquanto texto (aqui na acepção de Lotman), no sentido de elucidar as tramas composicionais aí urdidas. Para tanto, sua prática intelectual atua em largos campos de interesse, construindo um modo de pensar que segue em várias e seguras direçôes, pois sempre respeita as nuances e particularidades de cada texto de cultura.

Em suas visadas investigativas, o centro e as bordas do tecido cultural encontram-se num jogo dialético provocante. O lugar de análise percorre vãos que incidem tanto sobre acervos canônicos quanto os em construção e em conquista territorial, numa equalização de valores que permitem cruzamentos culturais os mais instigantes.

Sua atividade acadêmica, como docente e pesquisadora, segue a mesma linha de envolvimento múltiplo de disseminação teórica e cultural. Suas aulas contêm sutis estratégias de sedução temática e intelectual, angariando ganhos de afetividade junto à audiência. Um dado perceptivo desta marca é sua oratória, flagrantemente cúmplice de suas pesquisas em oralidade. Jerusa ao falar póe o corpo em performance, revelando um dos centros irradiadores de sua presença acadêmica: o interesse por todas as manifestaçôes culturais regidas pela oralidade. Por conta disso, mantém o seu núcleo de pesquisa da oralidade, lugar de articulaçôes teóricas, e de inúmeras pesquisas e atividades. 
A tradução textual, na perspectiva de difusão de pensamento, é uma de suas tarefas também profícuas. Elegendo autores (como o medievalista Paul Zumthor), com quem dialoga profusamente, transfere-os para a língua portuguesa apropriando-se de suas ideias em cumplicidade reflexiva. Jerusa é uma tradutora atenta e faz desta atividade um modo de valoração da crítica e da divulgação científica.

Em sua produção ensaística encontramos variados estudos e análises sobre tradição oral e cultura popular, colocando tais temas em fricção com outros segmentos teóricos de estudos da cultura, de comunicação, antropologia, semiótica etc. Destaco, dentre outros títulos, o Armadilhas da Memória e outros ensaios. Lançado em 2004, pela Ateliê Editorial, o livro compóe-se de sete ensaios divididos em duas partes. Os escritos foram elaborados em momentos distintos, o que não compromete a taxa de regularidade das propostas investigativas em torno do tema geral da memória e seus desdobramentos.

O tratamento dado aos objetos estéticos e autores analisados se dá por um movimento de entrega que une intelecto e corpo, numa afinidade eletiva inarredável. Há como que, uma necessidade de presentificação daquilo que está sendo exposto, do que está sendo discutido, como tentativa de mostrar ao leitor como cada signo estético funciona.

$\mathrm{Na}$ primeira parte do livro, temos leituras pontuais de obras literárias e críticas, que evocam construçóes de memória. Em Caronte ou o Cronotopo de Evocação, a autora analisa o romance Caronte, do escritor baiano Antonio Brasileiro, sob o conceito bakhtiniano de cronotopo da evocação: "A instalação de um modo de evocar que introduz ou recupera toda uma interaçáo de sentidos recriados e bem presentes, em diversos tempos e espaços" (Jerusa, 2004). A leitura de Caronte recebe a incisiva abordagem deste conceito e o coloca como representativo de conquista de linguagem, da instalaçáo de uma poética do mito, que reverbera na construção da memória, em sua superposição de tempos e espaços presentes e míticos.

$\mathrm{Na}$ sequência da análise ao livro Caronte, Jerusa faz um breve comentário sobre uma exposição do pintor italiano Zoram Music, sob a mesma perspectiva do cronotopo de evocação, para tratar de arte e memória contra a morte. A avaliação das duas obras serve para a autora discorrer com pertinência sobre as múltiplas possibilidades da memória, pondo em causa o medo do esquecimento.

O segundo ensaio traz leituras da obra Rumor do Tempo e Viagem à Armênia, do escritor russo Óssip Mandelstam, pondo-os como "uma explosão do texto memorial". Jerusa aproxima as obras da tradição memorialista e do questionamento da identidade judaica a partir do percurso vivenciado e narrado pelo autor, da infância à idade adulta, fazendo o levantamento dos repertórios, livros e leituras apontados por Mandelstam, 
para, junto com ele, captar "processos de cultura e da escritura." A leitura apresentada detecta a "memória como uma investida discursiva e, ao mesmo tempo, construção lógica, imagem e conceito, comportando permanentemente definiçóes.”

Em De poética, politica e memória, terceiro ensaio do livro, a autora comenta duas obras do escritor albanês Ismail Kadaré. No romance As frias flores de abril, são apontados aspectos da história política da Albânia, como a ocupação stalinista e a tradição cerceadora do Kanum e seus efeitos, com o uso alegórico da fábula mítica de Eros e Psiquê para construir uma discussão sobre o exercício de liberdade. Já em sua leitura sobre o romance Abril despedaçado, há uma associação da tragédia e das contingências que limitam e aprisionam o indivíduo, a aridez e o isolamento da montanha, encontrados na narrativa, com a realidade do sertão brasileiro. Destacando a transposição cinematográfica feita pelo cineasta brasileiro Walter Salles, Jerusa vê uma justa aproximação ao sertão: "a solidão, a ética, o cânone moral e a miséria são trazidos em comparação", embora acuse no filme certa ausência do clima trágico encontrado no romance. $\mathrm{O}$ autor Ismail Kadaré é colocado em elevado valor literário, com sua poética que configura grandezas de linguagem ao reunir "o momento à eternidade, o político, como um todo, ao imediato e contingente."

Cultura é memória, o quarto ensaio, talvez seja o que centralize e conceitue melhor o que pensa a autora sobre memória e cultura. Apresentando o semioticista Iuri Lotman como um dos mais importantes pensadores das ciências sociais do século XX, a autora reúne e discute algumas teses centrais da obra do russo, como, por exemplo, o conceito de cultura, que Lotman desenvolve associando-o à História e à Comunicação. A cultura, enquanto procedimento semiótico, é, para Lotman, informação, codificação, transmissão e memória.

A presença de Lotman no pensamento universitário brasileiro é apontada por Jerusa como imprescindível. A noção de tipologia da cultura serve de base para avaliação de séries culturais com as quais a autora desenvolve suas pesquisas, no âmbito da cultura popular e da tradição oral.

E quanto à discussão de memória, a autora afirma, juntamente com Lotman, que cultura é memória e se dirige contra o esquecimento. E como cultura é um mecanismo de organização e conservação das afirmaçôes, está relacionada à longevidade.

Portanto, a semiótica da cultura desenvolvida por Iuri Lotman é seguida de perto por Jerusa, que afirma, num tom assumidamente reverente: "tendo sempre presentes os atos de escolha, as rupturas, o pensamento, a consciência, este pensador lido ou relido nos leva descobrir o que estávamos querendo, o que já pressentíamos tantas vezes, e só depois de lê-lo, então, pudemos presentificar." 
A questão da memória, relacionada à poesia popular, tem um traço de avaliação que é o esquecimento, a falha da memória. A autora discute magistralmente tal condição no primeiro ensaio da segunda parte do livro: $O$ esquecimento, pivô narrativo. Curiosa discussão, trazendo exemplos vários do acervo da tradição de poesia popular, em que o esquecimento na narrativa é detectado, formando uma espécie de morte momentânea ritualizada, em que o lapso, a fratura, o hiato têm a ver com a ação de narrar.

Citando Lévi-Straus a autora afirma que o esquecimento é verdadeiramente o responsável pela continuidade, pela memória e pela lembrança. O esquecimento serve mesmo para quebrar a continuidade na ordem mental, para fundamentar interdiçóes, e isso é próprio da narrativa, é realmente seu pivô.

Na literatura popular o motivo do "Reino do Vai náo Torna" está sempre presente, a noção de inferno, de onde não se retorna. É esta temática que Jerusa desenvolve no segundo ensaio da segunda parte do livro, fazendo uma relação da ocorrência deste motivo no mundo arturiano, sobrenatural, céltico e no sertão. A tradição oral nordestina é posta em destaque com uma escuta empreendida em folhetos de cordel, associando o tema do vai não torna a condiçóes existenciais do nordestino, como os fenômenos da seca e da migraçáo expressados nas narrativas, e como diz a autora, "a morte aqui fantasiada não é a alegoria de alguma coisa distante. É o dia-dia trágico que se presencia na cidade e no campo."

Encerrando o livro a autora traz a análise de um formato tradicional encontrado na poesia popular: a peleja. Em Um gosto de disputa. Um combate imaginário há um cuidadoso estudo sobre a disputa, o torneio, o combate, forma recorrente na literatura conhecida como de cordel, em que dois trovadores, cantadores confrontam-se numa lide poética. $\mathrm{O}$ manejo da palavra nesses combates imaginários, apoiado em intensa semantização garantem a preservação e a memória.

Armadilhas da memória é a própria face ou faces de Jerusa Pires Ferreira, sua entrega analítica aos sujeitos e objetos encanta, suas performances teóricas em busca de construçôes de texto de cultura, revelam uma semiosfera convidativa e aliciadora.

\section{$\operatorname{son}$}

\section{Resumo}

O presente artigo é um depoimento que aponta para o percurso intelectual e acadêmico da professora e pesquisadora Jerusa Pires Ferreira, destacando sua contribuição docente e teórica em torno de questóes da semiótica da cultura, e dos caminhos e avanços da pesquisa em oralidade no 
Brasil e no mundo. Para tanto, o artigo apresenta e explora a obra Armadilhas da Memória e outros ensaios, livro publicado pela autora em 2004.

\section{Abstract}

This article focuses on the intellectual and academic route of professor and researcher Jerusa Pires Ferreira, highlighting her teaching and theoretical contribution surrounding the issues of cultural semiotics, and the paths and advances of research on orality in Brazil and worldwide. For this purpose, the article presents and explores the work Armadilhas da Memória e outros Ensaios, a book published by the author in 2004 .

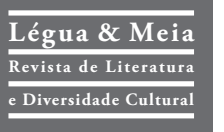

FILHO, Feliciano José Bezerra. A memória viva gerada por Jerusa. Légua \& Meia: Revista de literatura e diversidade cultural. Feira de Santana: UEFS, A. 14, nº 7, 2016, p 229-233.

Feliciano José Bezerra Filho é Professor adjunto da UESPI. Graduado em Letras pela UFPI, Mestre e Doutor em Comunicação e Semiótica pela PUC/SP. Publicou o livro A Escritura de Torquato Neto (2004), dentre outros ensaios e artigos científicos. É também músico e compositor. 